\section{EXPERIMENTAL ANALYSIS OF THE VISCOUS TUNED MASS DAMPER FOR THE ATTENUATION OF STRUCTURAL RESPONSES}

\author{
Afham Zulhusmi Ahmada*, Aminudin Abua, Lee Kee Quena, \\ Nor'azizi Othmana, Faridah Che In ${ }^{b}$ \\ alntelligent Dynamic System, Malaysian-Japan International \\ Institute of Technology (MJIIT), Universiti Teknologi Malaysia, \\ Malaysia \\ bCommerce Department Politeknik Kuching Sarawak, \\ Malaysia \\ Accepted \\ 9 September 2021 \\ Published Online \\ 20 October 2021 \\ *Corresponding author \\ azulhusmi2@graduate.utm.my
}

Article history

Received

9 June 2021

Received in revised form

1 September 2021

\section{Graphical abstract}

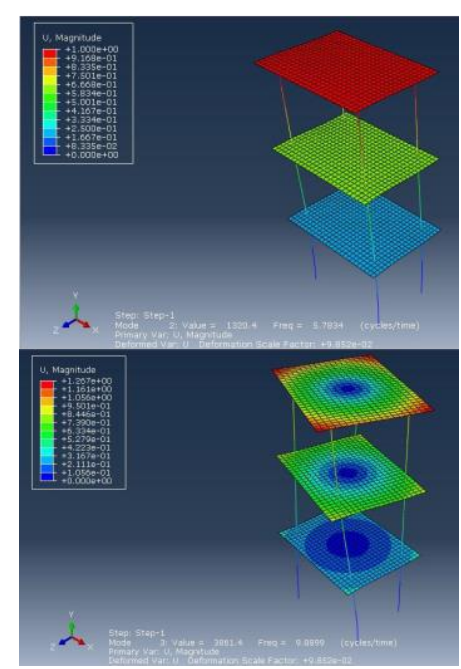

\begin{abstract}
This paper presents a systematic experimental investigation on the performance of a Multiple Tuned Mass Dampers (MTMDs) attached to a structural system under dynamic load excitation. A Modal Experimental Analysis (EMA) of a three-story structural frame equipped with a viscous damper system was carried out through a series of shaking table tests to evaluate the performance and verify the analysis approach. Each of the TMDs consists of a mass attached to a structural floor via Thermoplastic Polyurethane (TPU) viscous bearing. Initially, the TMD was designed solely to control single mode vibration and then the mechanism is extended for the application of controlling multimode responses. The experiment demonstrated that the proposed viscous dampers exhibit good performance in reducing the response of structures under dynamic loads, and able to control both fundamental and higher vibration modes of a Multiple Degree of Freedom (MDOF) primary system effectively. It was also evident that the attachment of the air dashpot dampers to each of TMDs lead to better efficiency on controlling the amplification of the damper mass and significantly contribute to better structural modal tuning.
\end{abstract}

Keywords: Tuned mass damper, experimental modal analysis, modal tuning, viscous bearing, thermoplastic polyurethane

\begin{abstract}
Abstrak
Makalah ini membentangkan penyelidikan eksperimental sistematik bagi mengkaji keberkesanan Peredam Jisim Boleh Laras Berganda (MTMD) yang digabungkan kepada suatu struktur. Untuk menilai prestasi dan mengesahkan pendekatan analisis yang digunakan, Analisis Modal Eksperimental (EMA) kerangka struktur tiga tingkat yang dilengkapi dengan sistem peredam dilakukan menggunakan ujian meja goyang. Setiap peredam terdiri daripada jisim yang dilekatkan pada lantai struktur melalui penggalas Thermoplastic Polyurethane (TPU). Pada mulanya, peredam direkabentuk untuk mengawal getaran mod tunggal dan kemudian mekanisme diperluas kepada kawalan tindak balas multimod. Eksperimen menunjukkan bahawa peredam yang dicadangkan mempunyai prestasi yang baik bagi mengurangkan tindak balas struktur di bawah beban dinamik dan dapat mengawal kedua-dua mod getaran asas dan lebih tinggi bagi sistem kerangka primer dengan berkesan. Hal ini juga menunjukkan bahawa penyambungan peredam dashpot udara kepada sistem kawalan menyumbang kepada kecekapan yang lebih baik dalam mengawal getaran struktur dan menyumbang kepada penalaan modal struktur yang lebih baik.
\end{abstract}

Kata kunci: Jisim boleh laras, analisis modal eksperimen, penalaan modal, galas likat thermoplastic polyurethane

(C) 2021 Penerbit UTM Press. All rights reserved 


\subsection{INTRODUCTION}

Supplemental passive strategies offer an attractive means towards incurring unnecessary natural expenditures. Tuned mass damper is a classical edition of passive device which consists of mass moves relative to the primary structure attached in parallel to the structure by stiffness and viscous damping elements. This provides a frequency-dependent hysteresis that increases damping in the primary structure. The damper frequency is tuned to the primary structure to allow the TMD resonate out of phase with the structural motion within the excitation frequency. As a result, the lightly damped fundamental mode of primary structure is transformed into two coupled damped modes. Its capability of attenuating undesirable vibrations relies on certain advantages through a robust design configuration with no effects on high temperature, an inexpensive solution, and provides large structural damping. The use of tuned mass dampers have been widely implemented in monumental landmarks including at the C N tower Toronto of Canada, Sydney Tower of Australia, Crystal Tower of Japan, Taipei 101 Tower of Taiwan, and recently at Air Traffic Control Tower of India [1].

The tuned mass damper's (TMD) key drawbacks are its sensitivity to fluctuations in tuning its natural frequency to the controlled natural frequency of a structure, and its lack of dampening control. Mistuning or off-optimal damping can greatly impair the TMD's effectiveness, implying that a single TMD is not very resilient. Furthermore, due to the decrease of structure rigidity, the dynamic characteristics of structures would alter during intense earthquakes. Owing to the offset in frequency tuning and the ideal damping ratio, this adjustment will significantly decrease the performance of a single TMD. As a result, using multiple TMDs with distinct dynamic properties can improve the TMD's effectiveness and resilience.

\subsection{LITERATURE REVIEW}

Many studies have recognized the potentials of using numerous TMDs to improve the robustness of a system over time. In order to augment the dissipation energy in a TMD, it is initially crucial to determine its optimum parameter known as the optimum tuning frequency ratio and the optimum damping. [2], [3], and [4] proposed a conceptual multiple TMD to control variable frequencies in structural vibration. The mechanism may be achieved through the design of optimum parameters for each TMDs for distribution of control system around the structure's primary natural frequency. [5] conducted a study to determine the characteristics and performances of multiple TMD using the perturbation technique and later, [6] extended the study by considering random excitation. For a finite number of multiple TMD, [7] designed the optimum parameters of multiple TMD for both undamped and damped primary structure. In order to attenuate undesirable vibration, [8] proposed multiple TMD with a uniform distribution of natural frequencies. The result revealed that TMDs with identical stiffness and damping coefficient but unequal mass and damping ratio demonstrated the best effectiveness and robustness. [9] then proposed a gradient-based method for optimizing non-uniformly distributed multiple TMD and the result demonstrated that the proposed arrangement is more effective than the traditional optimal uniformly distributed multiple TMD.

Meanwhile, the analytical results in studies by [4] and [10] demonstrated that numerous TMD strokes can be greatly reduced while structural control effectiveness is maintained. To minimize unwanted vibration of floor constructed with longer span, [11] and [12] proposed the use of an innovative configuration of distributed multiple viscoelastic TMD. By taking account on the damper location, the installed damper system successfully attenuated floor response to an acceptable limit for human comfort. A study by [13] integrated the concept of Floor Isolation System and TMD to produce a large mass ratio without additional masses. According to results from the numerical and experimental processes, the absolute acceleration of TMD floors is lesser than the main structure, indicating that the arrangement maintains the merit of the Floor Isolation System. Meanwhile, [14] investigated the response of a 76-storey benchmark building equipped with distributed multiple TMD. The data revealed that distributed multiple TMD is more effective than single TMD in controlling the first five structural modes.

[15] investigated the effectiveness of the multimode control of chimneys subjected to ground excitations. Within the study, it was concluded that the performance of TMDs dedicated to control different modal response is better compared to the one which was designed to control fundamental modal response. [16] proposed an innovative design of multiple TMD by benefiting partial floor loads at limited number of structural floors. Increase in mass ratios and the number of floors utilized as TMDs reportedly improve structural responses during earthquakes. [17] compared the distributed multiple TMDs' system performance against that of passive friction dampers, semi-active dampers, and a single TMD. It was indicated that the recommended system surpasses a convenient placement in terms of space restrictions. To preserve ceramic electrical equipment such as Potential Transformers (PT) from damage during an earthquake, [18] suggested a novel multiple TMD for a $220 \mathrm{kV}$ PT but the influence of various factors such as the number of mass units and mass ratio must first quantitatively evaluated. According to the experimental validation, the PT which was regulated with multiple TMD can resist a 30 percent stronger earthquake than a noncontrolled situation. [19] suggested a methodology for designing a robust multiple TMDs for a 10-storey building and the result suggested that (result). In addition, [20] and [21] also recommended that the vibration control of multiple TMDs is more efficient when the dampers are 
strategically placed to the structural floors with the maximum amplitude in the mode shapes accordingly. [22] and [23] concluded from their study on the optimization of multiple TMD that by increasing the number of TMDs, the frequency ratio bandwidth becomes wider and decreases equivalent damping ratio subsequently.

Generally, a single TMD is designed to control fundamental vibration mode and restricted to encounter narrowband vibration frequency. In order to counter the particular drawback and enable its potential to control wideband frequency, a multiple TMD mechanism is needed [24]. Therefore, this study initially presents the modelling of a three-storey structural system which is then validated experimentally using electrodynamic shaker. In order to develop the proposed vibration control mechanism, the TMD is designed according to the identified dynamic properties of structural system. Basically, the TMD mechanism consist of three basic components which are Thermo-plastic Polyurethane (TPU) high damping bearing, aluminium mass, and air damper. The mechanism is attached to the structural system based on different cases of single and multiple TMDs. The data analysis was conducted extensively for both frequency and time domain, with additional peak response ratio analysis to identify the performance of control mechanism. Comparing both single and multiple TMD mechanism, it can be concluded that both arrangements are able to supress Root Mean Square (RMS) acceleration and displacement significantly. However, from the peak response analysis, the multiple TMD is proven to perform better in controlling all structural vibration modes.

\subsection{MODELLING OF STRUCTURAL SYSTEM}

The analysis of a structural dynamic properties commences at its equations of motion modelling. The modelling approach purposefully describe the structural dynamic response using second-order linear differential equations which directly correlate physical parameters (mass, damping, and stiffness) to the structural dynamic characteristics in terms of mode shapes and modal frequencies [25]. A 3-storey structural frame is considered as the experimental rig that represent the uncontrolled Primary Structure (PS) as illustrated in Figure 1.

The equations of motion can be obtained as a single matrix equation using $x_{1}, x_{2}$, and $x_{3}$ as the coordinates to represent the displacement vibration of the system. The following matrix equation denotes a general form of matrix representation:

$[M]\{\ddot{x}\}+[C]\{\dot{x}\}+[K]\{x\}=\{0\}$

The mass, damping, and stiffness matrices are $[M],[C]$, and $[K]$. Mathematically, the non-trivial solution to Equation $l$ is the free vibration solution. It should be written in the following format:
$\{x\}=\{X\} \sin \omega t$

When this type of answer is substituted into Equation 1, it produces the following algebraic matrix equation:

$\left([K]-\omega^{2}[M]\right)\{X\}=\{0\}$

In order for this equation to have a non-zero solution $\{X\},\left([K]-\omega^{2}[M]\right)$ must be singular, as follows:

$\left|[K]-\omega^{2}[M]\right|=0$

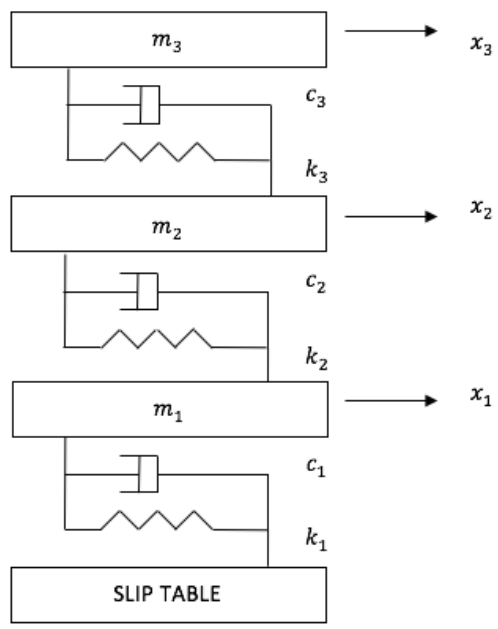

Figure 1 Modelling of 3 DOF systems

This is the equation for the system's properties. The natural frequencies are the solutions to this equation. Equation 3 is an eigen-value solution, which $\omega^{2}$ is referred to eigen-value while $\{X\}$ is represented as the eigen-vector. In order to depict the structural system, a finite element modelling of the PS system was designed using ABAQUS by defining the material properties as displayed in Table 1. The boundary condition defined is fixed at the ground level and free at the top floor which means it is free to move along $Y$ axis and rotate about $Z$ and $X$ axis. For frequency extraction analysis, eigenvalues solvers were set as Lanczos with 10 requested eigenvalues number. Referring to Figure 2, the structure has 3 identical mode shapes within the analysis bandwidth. The first mode and second mode responded in longitudinal form while the third mode deformed in transverse and torsional form.

Table 1 Material Properties of Structural Frame

\begin{tabular}{|l|c|c|}
\cline { 2 - 3 } \multicolumn{1}{c|}{} & \multicolumn{2}{c|}{ Materials } \\
\hline Properties & Steel Stud & $\begin{array}{c}\text { Concrete } \\
\text { Plate }\end{array}$ \\
\hline Poisson's ratio & 0.3 & 0.2 \\
\hline Young Modulus (GPa) & 200 & 18 \\
\hline Density $\left(\mathrm{kg} / \mathrm{m}^{3}\right)$ & 7800 & 2310 \\
\hline
\end{tabular}




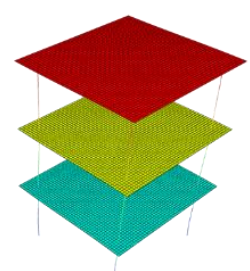

(a)

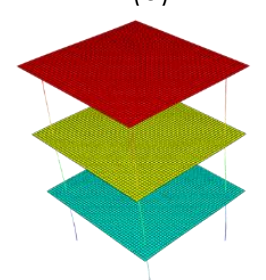

(b)

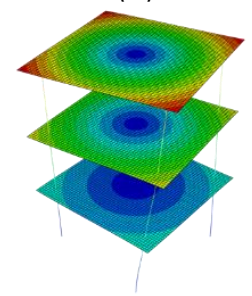

(c)

Figure 2 ABAQUS Finite Element Simulation (a) Model (b) Mode 2 (c) Mode 3

\subsection{Experimental Rig Setup}

The experimental verification of design model modal is essential [26] in the field of structural dynamics. Hence, frequency domain modal analysis has been implemented within this study to carry the experimental modal analysis named as Frequency Response Function (FRF). Generally, an FRF in experimental modal analysis is a frequency-based function used to identify the resonant frequencies, damping, and mode shapes of a physical structure. In other words, it is referred to a transfer function between the input and output in terms of frequency domain expression of a linear time invariant system.

There are several systems of input excitations and response outputs that can be used to calculate the experimental FRF such as mechanical, acoustical, rotational mechanical, and combined acoustic mechanical systems. Figure 2 depicts an idealised measurement condition in which there is no noise and no measurement mistakes. The FRF is just the ratio of two Fourier transforms, with response $x(t)$ designated by $X(\omega)$ and input force designated by $F(\omega)$ :

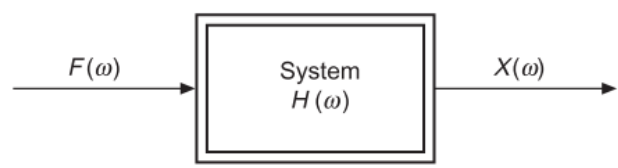

Figure 3 A Systems with Single Input and Output
$H(\omega)=\frac{X(\omega)}{F(\omega)}$

In order to mimic a fixed-free boundary condition structural model, a physical 3-storey structural frame was constructed which consists of concrete plates and steel studs. Each of concrete plate has its own mass which are $11.124 \mathrm{~kg}$ for the first floor, $10.687 \mathrm{~kg}$ for the second floor, and $9.349 \mathrm{~kg}$ for the third floor. The dimension of all plates designed as length $L=508 \mathrm{~mm}$ and width $W=508 \mathrm{~mm}$, and tied to four studs of diameter $\mathrm{d}=8 \mathrm{~mm}$ and length $\mathrm{L}=1800 \mathrm{~mm}$. For experimental modal analysis as shown in Figure 4, the primary structure is tied to the slip table, while the electrodynamic shaker is connected horizontally to the slip shaker. Forces have been applied via electrodynamic shaker, and measurement of structural responses are measured using accelerometers. Various excitation input can be simulated by the shaker which for this case, a sine sweep signal was selected as the input signal.

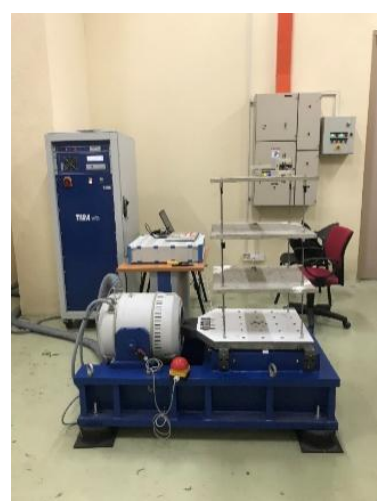

Figure 4 General Experimental Setup

An accelerometer has been placed at measurement points to measure and acquire the response data signal in the form of voltage. The sensitivity of accelerometers for the first, second, and third floor are $104.95 \mathrm{mV} / \mathrm{g}, 100.17 \mathrm{mV} / \mathrm{g}$, and 101.5 $\mathrm{mV} / \mathrm{g}$. The reference force transducer located at the slip table is $198.7 \mathrm{mV} / \mathrm{g}$ and the sine sweep signal has been used for the excitation input signal. This signal consists of sinusoidal wave which is continuously swept through the frequency range of interest. The advantage of using this type of signal is to achieve better signal-to-noise ratio. Before the FRF data can be produced from the measured force and reaction data, the signal is processed by a signal conditioner.

The structural ground floor was subjected to a broadband vibration induced by an electromagnetic shaker to acquire the structure's modal characteristic. Each excitation is measured for 15 seconds to achieve a frequency resolution of $0.1 \mathrm{~Hz}$, which represents the time it takes for vibrations on the transfer function and resonance peaks to dampen out sufficiently [27]. The 
experimental FRF, which is defined as the ratio of the cross-PSD of the input force signal, is calculated using the $\mathrm{Hl}$ estimator. The structure's damping ratio, frequency, and mode forms are calculated by converting the output acceleration signal to the input force signal's auto-PSD. The following parameters were used to estimate the data in the temporal domain to transfer functions of the accelerometer mounted within each point; block size of $5 \mathrm{~s}$; Hanning window; average of 15; and $50 \%$ overlapping. The structure's modal damping is calculated from the transfer function using the half power bandwidth approach [28]. Table 2 shows the validation of natural frequency between the simulation and experimental procedures. This validation is purposely conducted to justify the credibility of the experimental set up and procedures. By referring to the data, the discrepancies of each structural modes between simulation and experimental method considered minimal and acceptable with the highest relative difference is $19.8 \%$ which refer to the first mode.

Table 2 Modal Analysis of Primary Structure

\begin{tabular}{|l|c|c|c|}
\hline & $\begin{array}{c}\text { Simulation } \\
(\mathbf{H z})\end{array}$ & $\begin{array}{c}\text { EMA } \\
\mathbf{( H z )}\end{array}$ & $\begin{array}{c}\text { Difference } \\
\mathbf{( \% )}\end{array}$ \\
\hline Mode 1 & 5.4894 & 4.4 & 19.8 \\
\hline Mode 2 & 5.4894 & 5 & 8.9 \\
\hline Mode 3 & 7.7961 & 8.7 & 11.6 \\
\hline
\end{tabular}

\subsection{Design \& Fabrication of TMD}

As shown in Figure 5, the proposed viscoelastic bearing is made up of two plates restraint and bonded together to form a Thermo-plastic Polyurethane high damping bearing. The following is a basic method for constructing an ideal bearing for the proposed TMD. This approach uses an approximate mathematical solution to discover out on dynamic characteristics of a visco-elastic damper. The following is a synopsis of the procedure:

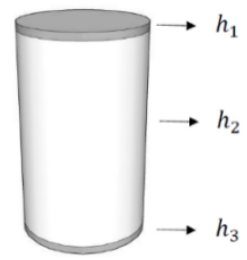

Figure 5 Thermoplastic Polyurethane (TPU) Bearing Diagram

\section{Step 1:}

Determine the primary system's basic dynamic properties (i.e., $f_{1}, \xi_{1}$, and $m_{1}$ for an analogous SDOF system) that will be retrofitted with a damper. The asbuilt conditions of the floor will be used to determine these attributes. This ensures that the damper built can inhibit a particular mode of floor vibration.

\section{Step 2:}

Using Equation 6, calculate a damper mass ratio $(\mu)$ that is appropriate based on the physical restrictions as well as the necessary decrease in the primary system's response.

$\mu=\frac{m_{\text {end }}}{\phi_{i}^{T}[M] \phi_{i}}$

Step 3:

Equation 7 can be used to measure the TMD's optimum natural frequency, $f_{2}$, based on the defined mass ratio.

$f_{2}=\frac{f_{1}}{1+\mu}$

Step 4:

Based on the stated mass ratio, Equation 8 can now be utilised to estimate the ideal damping ratio of the TMD $\left(\xi_{2}\right)$.

$\xi_{\text {opt }}=\sqrt{\frac{3 \mu}{8(1+\mu)^{3}}}$

\section{Step 5:}

Modify the damper's trial dimensions (i.e., $h_{1}$ (thickness of upper layer constraint), $h_{2}$ (thickness of viscoelastic core), $h_{3}$ (thickness of lower layer constraint), $L$ (length of viscoelastic bearing), and $d$ (diameter of viscoelastic bearing) as shown in Figure 5 to accommodate any physical limitations. Furthermore, the confining layers' and viscoelastic material's material properties must be determined. ( $E_{1} \& E_{3}$ for the layers of constraint and $\beta$ \& $G$ in the case of visco-elastic materials). For convenience of usage, the top and bottom layers might be made of the same material. (i.e., $E_{1}=E_{3}$ ).

\section{Step 6:}

In the case of a cantilever sandwich beam with no end mass, Equation 9 is used to calculate the wave number $\left(K_{B}\right)$.

$$
K_{B}=\frac{1.875}{L}
$$

\section{Step 7:}

a damper with a lump at the end has a natural frequency can be calculated by Equation 10.

$$
f_{2}=\frac{1}{2 \pi} \sqrt{\frac{k_{2}}{m_{2}}}
$$

where $k_{2}$ is the modal stiffness of the cantilever beam and $m_{2}$ is the modal mass of the cantilever beam. Equation 11 can be used to calculate the modal stiffness of a cantilever beam $\left(k_{2}\right)$.

$$
k_{2}=\frac{3(E I)_{\text {total }}}{L^{3}}
$$

The modal mass of a uniform viscoelastic cantilever beam having a mass at the end can be calculated using Equation 12.

$$
m_{2}=\frac{33}{140} \rho A L+m_{\text {end }}
$$


$\rho$ is the sandwich beam's mass density, $A$ is its crosssectional area in total, and $m_{\text {end }}$ is the end mass at the tip of a sandwich cantilever beam. The damper frequency is fine-tuned using the end mass, which is useful in reducing floor vibrations.

\section{Step 8:}

Make a calculation for the overall loss factor due to dissipation and estimate damping ratio $\left(\xi_{2}\right)$ using Equation 13.

$$
\eta=2 \xi_{2}=\frac{\beta g_{e}^{\prime} Y}{1+g_{e}^{\prime}(2+Y)+g_{e}^{\prime}(1+Y)\left(1+\beta^{2}\right)}
$$

$g_{e}^{\prime}$ is the cantilever's shear parameter sandwich beam with end mass, and $Y$ is the geometric parameter obtained. Because the wave number value is proportional to the frequency, the system's wave number value changes when the effect of the additional end mass on the system's natural frequency is taken into consideration, as stated in Equation 14.

$$
K_{B}^{2}=2 \pi f_{2} \sqrt{\frac{\rho A}{(E I)_{\text {total }}}}
$$

In order to solve Equation 13, the shear parameter can be determined as follow

$$
g_{e}^{\prime}=\frac{G b}{2 \pi h_{2} f_{2}} \sqrt{\frac{(E I)_{\text {total }}}{\rho A}}\left(\frac{1}{E_{1} A_{1}}+\frac{1}{E_{3} A_{3}}\right)
$$

This technique must be repeated until the appropriate damper qualities are reached by adjusting the viscoelastic damper's material and dimensions. One of the most critical parameters affecting the efficiency of a damper made of viscoelastic material is the rubber dissipation loss factor $(\beta)$. For the rubber shape to be employed, this material property must be computed.

Table 3 Design of Viscoelastic Bearing for the TMD

\begin{tabular}{|l|c|c|c|}
\cline { 2 - 4 } \multicolumn{1}{c|}{} & MODE 1 & MODE 2 & MODE 3 \\
\hline Length, $L(\mathrm{~m})$ & 0.027 & 0.022 & 0.017 \\
\hline Diameter, $d(\mathrm{~m})$ & 0.017 & 0.02 & 0.03 \\
\hline $\begin{array}{l}\text { Thickness of steel top } \\
\text { constraining layer, } h_{1} \\
(\mathrm{~m})\end{array}$ & 0.001 & 0.001 & 0.001 \\
\hline $\begin{array}{l}\text { Thickness of rubber, } \\
h_{2}(\mathrm{~m})\end{array}$ & 0.025 & 0.02 & 0.015 \\
\hline $\begin{array}{l}\text { Thickness of steel } \\
\text { bottom constraining } \\
\text { layer, } h_{3} \text { (m) }\end{array}$ & 0.001 & 0.001 & 0.001 \\
\hline $\begin{array}{l}\text { Cross-sectional area, } \\
A \text { (m) }\end{array}$ & $2.27 \mathrm{E}-04$ & $3.14 \mathrm{E}-04$ & $7.07 \mathrm{E}-04$ \\
\hline $\begin{array}{l}\text { Distance between } \\
\text { top \& bottom } \\
\text { constraining plate } \\
\text { centroid, } d_{c}(\mathrm{~m})\end{array}$ & 0.026 & 0.021 & 0.016 \\
\hline $\begin{array}{l}\text { Mass density of } \\
\text { rubber, } \rho\left(\mathrm{kg} / \mathrm{m}^{3}\right)\end{array}$ & 1100 & 1100 & 1100 \\
\hline $\begin{array}{l}\text { Dissipation loss factor } \\
\text { of rubber/TPU, } \beta\end{array}$ & 0.1008 & 0.1478 & 0.1241 \\
\hline
\end{tabular}

\begin{tabular}{|l|c|c|c|}
\cline { 2 - 4 } \multicolumn{1}{c|}{} & MODE 1 & MODE 2 & MODE 3 \\
\hline $\begin{array}{l}\text { Shear modulus of } \\
\text { rubber, } G\left(\mathrm{~N} / \mathrm{m}^{2}\right)\end{array}$ & $1.40 \mathrm{E}+06$ & $1.40 \mathrm{E}+06$ & $1.40 \mathrm{E}+06$ \\
\hline End mass, $m_{\text {end }}(\mathrm{kg})$ & 1.558 & 1.558 & 1.558 \\
\hline $\begin{array}{l}\text { Modal mass with } \\
\text { end mass, } m_{2}(\mathrm{~kg})\end{array}$ & 1.560 & 1.560 & 1.561 \\
\hline $\begin{array}{l}\text { Natural frequency of } \\
\text { damper, } f_{2} \text { (Hz) }\end{array}$ & 4.4 & 5 & 8.7 \\
\hline $\begin{array}{l}\text { Damping ratio of } \\
\text { damper, } \xi_{2}\end{array}$ & 0.0504 & 0.0738 & 0.0613 \\
\hline $\begin{array}{l}\text { Modulus of elasticity, } \\
E\left(\mathrm{~N} / \mathrm{m}^{2}\right)\end{array}$ & $2.00 \mathrm{E}+11$ & $2.00 \mathrm{E}+11$ & $2.00 \mathrm{E}+11$ \\
\hline Moment of inertia, $I$ & $4.1 \mathrm{E}-09$ & $7.9 \mathrm{E}-09$ & $3.98 \mathrm{E}-08$ \\
\hline $\begin{array}{l}\text { Modal stiffness of } \\
\text { cantilever beam, } k_{2} \\
\text { (N/m) }\end{array}$ & 1192 & 1539 & 4665 \\
\hline $\begin{array}{l}\text { Total flexural rigidity, } \\
(E I)_{\text {total }}\end{array}$ & 0.0078 & 0.0055 & 0.0076 \\
\hline Wave number, $K_{B}$ & 12.4983 & 15.8064 & 23.4837 \\
\hline Shear parameter, $g^{\prime}$ & 0.0003 & 0.0002 & 0.0001 \\
\hline $\begin{array}{l}\text { Geometric } \\
\text { parameter, } Y\end{array}$ & 9356401 & 4410000 & 1137777 \\
\hline $\begin{array}{l}\text { Overall dissipation } \\
\text { loss factor, } \eta\end{array}$ & 0.1008 & 0.1476 & 0.1226 \\
\hline
\end{tabular}

The first three modes of the structure were supposed to be controlled in this experimental work. As a result, each TMD mechanism now has three types of TPU bearings; one is set to the fundamental frequency, while the other two are tuned to the natural frequencies of the second and third modes. The first, second, and third modes of TMD are referred to as such. Each damper mass is made up of an aluminium plate that is vertically connected to structural floors and horizontally threaded to air dashpot dampers as displayed in Figure 6. Different combinations of air dampers are used to apply the shift in frequency for each damper. To determine the damper parameters, a single damper was installed at the top level, which was threaded horizontally to the air damper and assembled vertically by the TPU bearing. The vibration test was carried out separately for each air damper valve position, beginning with the highest damping resistance (level 1) and ending with the lowest damping resistance (level 9).

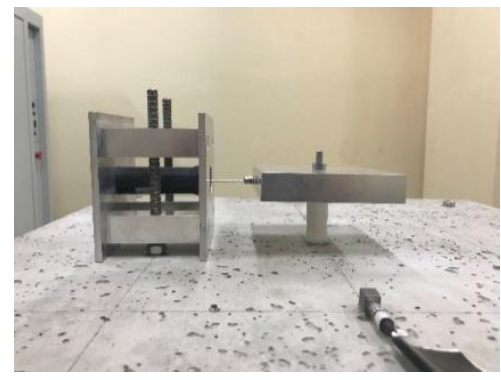

Figure 6 Proposed TMD Mechanism 


\subsection{RESULTS AND DISCUSSION}

The proposed TMD is evaluated under broadband excitation using TMD optimal parameters set to designated major structural modes. The uncontrolled primary structure scenario at various external dampening levels and tuned frequency ratios are investigated, in comparison to the tuned condition. The output criteria that are utilized to determine settings for best damping and tuning experiments are the transfer function calculation's highest peak amplitude over the measured range. The suggested TMD technique relies heavily on the damping assembly. An external damper and a suspended mass make up this system. The suspended mass mechanical energy is dissipated by the dashpot damper. The damper's dampening level is controlled by a valve. The assembling procedure is then thoroughly explained. A controlled external damper requires a dampening mechanism that can be adjusted as well as a way to change it. The external damper was chosen as an Airpot 2K160 air damper. The air damper's damping coefficient can be adjusted from 0 to $880 \mathrm{~N} /(\mathrm{m} / \mathrm{s})$, as well as the maximum pull and push loads ( 18 and $13 \mathrm{~N}$ ) using an adjustable valve. The air dampers are aligned with the shaker's excitation direction. Due to a ball joint, the air damper can be tightly applied to the hanging mass while enabling it to move independently. The valve positions are labelled from Level 1 through Level 9, with Level 1 representing the maximum resistance to dampening and Level 9 representing the lowest resistance to damping, as previously stated.

\subsection{Analysis of the Single TMD Mechanism}

Initially, the experiment is conducted with a single TMD that is tuned to various structural modes. Table 2 indicates that the EMA results have verified the existence of closely spaced modes which are generated due to the symmetrical architecture of the designated experimental rig. Therefore, the first two modes are significantly contributed to the overall structural vibration and the fundamental mode is a critical mode which is associated with the most severe structural responses. The TMD is positioned at the antinode of the mode, where it is most reliable. Since the uncontrolled primary structure procedure caused the largest steady state displacement on the top floor, a TMD is placed for the best control of the first mode which is referred to as TMDI. The same concept is applied for controlling the second and third modes where TMD is located at the first (TMD2) and second (TMD3) floor of the primary structure. The TMD arrangement is depicted in Figure 7. The following number after the control mechanism (TMD1, TMD2, and TMD3) varies from 1 to 9 in which number 1 represents the lowest damping resistance and number 9 represents the highest damping resistance of the air damper tuning level.
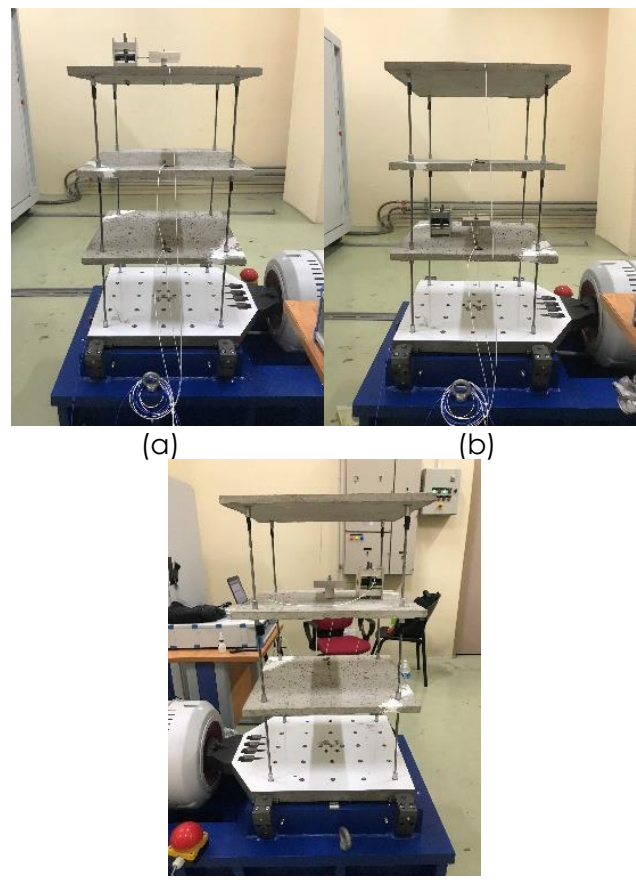

(c)

Figure 7 Arrangements of Single TMD (a) TMD1 (b) TMD2 (c) TMD3

Figure 8 elucidates the transfer function of the controlled primary structures. Generally, the natural frequency of the first two modes from the transfer function can be considered as a close mode. This situation is caused by the symmetrical component of the primary structure which led to the pairs of identical modes. The result indicates that the controlled primary structure shows lower natural frequency compared to the uncontrolled primary structure. The fundamental frequency is 3.9 for TMD18, $3.5 \mathrm{~Hz}$ for TMD27, while for TMD35 resulted at $3.3 \mathrm{~Hz}$. For the case of TMDI and TMD2 mechanism, primary structure responses found to be the most effective at level 8 and level 7 of the air damper valve position. However, for the TMD3 mechanism, the effective state goes to level 5 of the air damper valve position which is defined as the moderate damping resistance set up. Another interesting phenomenon that can be observed from the figure is that the off-resonance part of the transfer function which is lower compared to the uncontrolled case. This means that the control system is able to reduce structural vibration of the targeted mode for both resonance and off-resonance for all single TMD cases. 


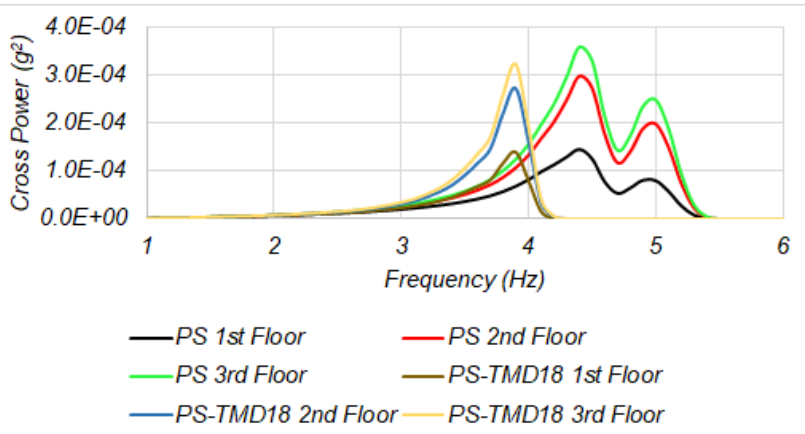

(a)
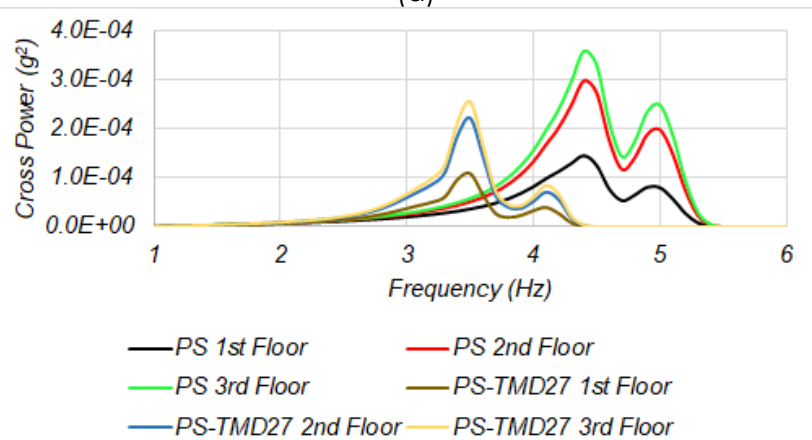

(b)

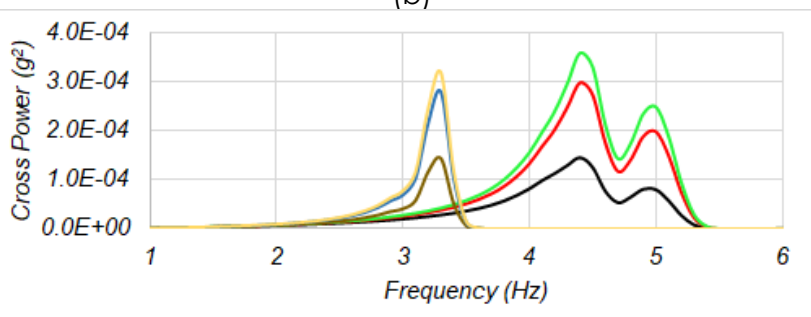

$\begin{array}{ll}\text { PS 1st Floor } & \text { PS 2nd Floor } \\ \text { PS 3rd Floor } & \text { PS-TMD35 1st Floor } \\ \text { PS-TMD35 2nd Floor — PS-TMD35 3rd Floor }\end{array}$

(c)

Figure 8 Fourier analysis results obtained from measured response acceleration for various single TMD mechanism arrangements (a)TMD18 (b)TMD27 (c)TMD35

The building structure with dampers mounted according to the first three cases in Table 3 were tested to identify the optimum tuning frequencies for each of the structural vibration modes according to their nominal damper frequency ratios. Table 4 summarizes the Root Mean Square (RMS) accelerations and displacements percentage reductions for different TMD mechanism arrangements. Under the base excitations, all three damper configurations perform admirably in terms of floors acceleration suppression. For the TMD 18 mechanism, the top floor acceleration can be decreased by 32.01 percent. According to the experimental results in Table 4, case TMD3 of air damper level 5 (TMD35) is the most efficient to reduce structural acceleration. This further confirms the theoretical expectation of control system under base excitation. The experimental results also show that all TMD cases are able to minimize top floor acceleration, due to an appropriate air damper tuning level. In reference to
Figure 9, despite of its capability to overrule other arrangements in terms of reducing acceleration responses, TMD35 also causes a significant reduction by $71.33 \%$ at the top floor RMS displacement, but it is $7.16 \%$ lesser compared to the TMD27 arrangement. These observations approved that by properly tuning the air damper, a single TMD mechanism is capable to perform well on the overall structural response reductions.

Table 4 RMS Acceleration and Displacement Reduction of Different Single TMD Cases

\begin{tabular}{|c|c|c|c|}
\hline TMD & Floor & $\begin{array}{c}\text { RMS } \\
\text { Acceleration } \\
\text { Reduction (\%) }\end{array}$ & $\begin{array}{c}\text { RMS } \\
\text { Displacement } \\
\text { Reduction (\%) }\end{array}$ \\
\hline \multirow{3}{*}{ TMD18 } & 1 & 27.24 & 22.27 \\
\cline { 2 - 4 } & 2 & 31.02 & 60.04 \\
\cline { 2 - 4 } & 3 & 32.01 & 69.69 \\
\hline \multirow{3}{*}{ TMD27 } & 1 & 28.70 & 50.60 \\
\cline { 2 - 4 } & 2 & 30.47 & 54.93 \\
\cline { 2 - 4 } & 3 & 32.02 & 78.49 \\
\hline \multirow{3}{*}{ TMD35 } & 1 & 37.83 & 35.40 \\
\cline { 2 - 4 } & 2 & 40.27 & 51.71 \\
\cline { 2 - 4 } & 3 & 41.94 & 71.33 \\
\hline
\end{tabular}
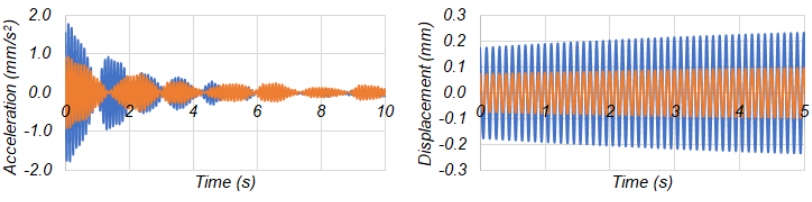

—PS 1st Floor —TMD35 1st Floor -PS 1st Floor —TMD35 1st Floor
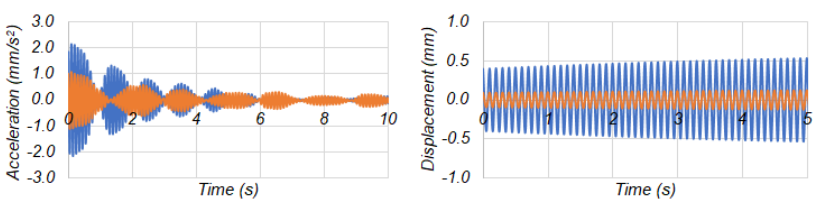

—PS 2nd Floor —TMD35 2nd Floor
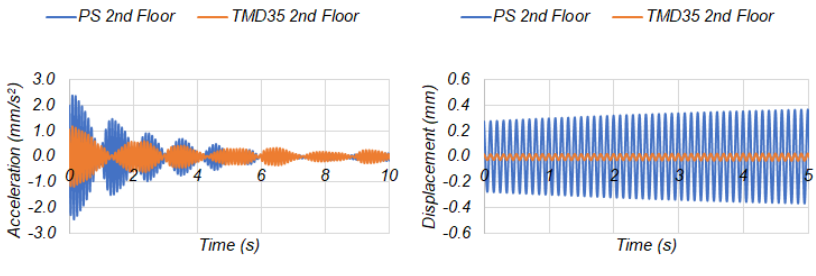

-PS 3rd Floor -TMD35 3rd Floor

—PS 3rd Floor —TMD35 3rd Floor

Figure 9 Acceleration and displacement responses of TMD35 mechanism

\subsection{Analysis of the Multiple TMD Mechanism}

In this section, the experimental procedures are conducted to control the presence of a second and third mode vibration of the primary structure. Primarily, a TMD is positioned at the top floor for all three cases in order to control the responses of the structural fundamental mode. This is because the first mode dominates the entire response of the primary structure. For the MTMD12 case, an additional TMD is located at the first floor which is dedicated to control second mode responses. However, the MTMD13 arrangement is 
supported by an additional TMD on the second level, while the MTMD123 arrangement has a single TMD on each of the primary structural floors. Only the top floor TMD air damper valve positions change irregularly from level 1 to 9, while the rest is set to its close position. The transfer function of the controlled primary structures is depicted in Figure 10. The controlled primary structure has lower fundamental natural frequency compared to the uncontrolled primary structure. The grids in Figure 10 demonstrate that the fundamental frequencies of MTMD12 tuned to air damper level 2 (MTMD122) is 3.4 $\mathrm{Hz}$, while for both MTMDI3 tuned to air damper level 2 (MTMD132) and MTMD123 tuned to air damper level 9 (MTMD1239) is $3 \mathrm{~Hz}$, respectively.
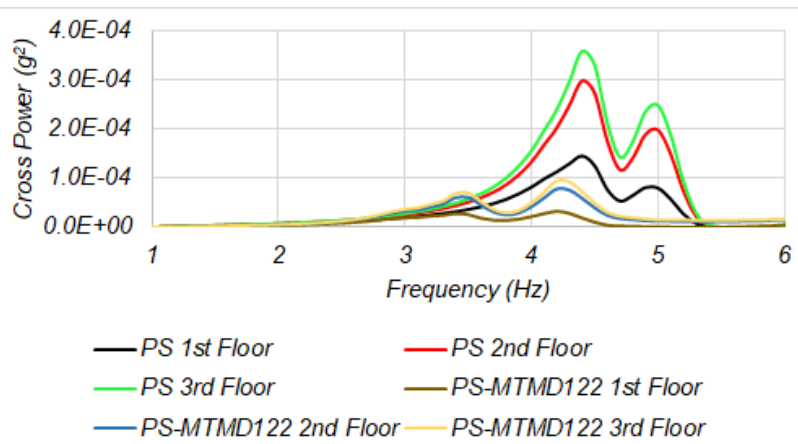

(a)
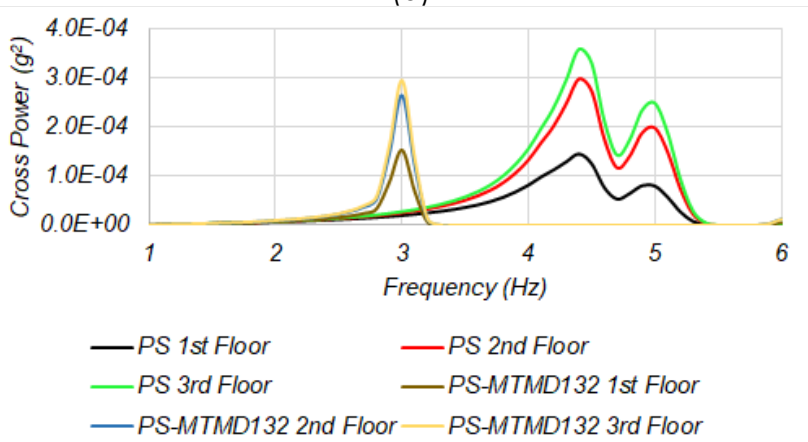

(b)
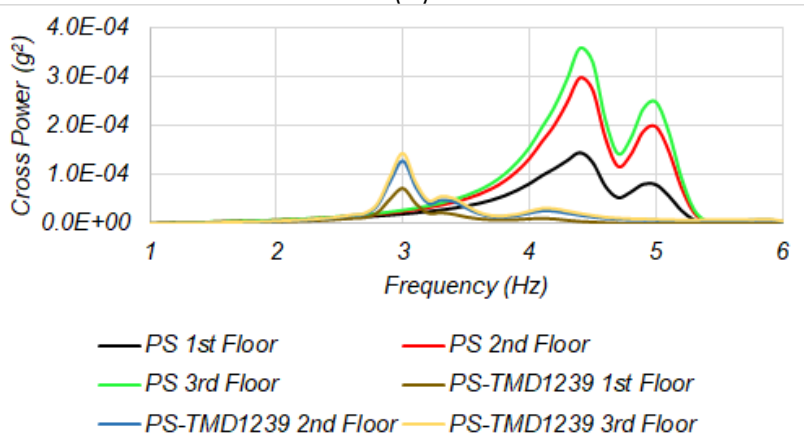

(c)

Figure 10 Fourier analysis results obtained from measured response acceleration for various multiple TMD mechanism arrangements (a)MTMD122 (b)MTMD132 (c)MTMD123

Figure 11 describes three damper configurations that are proposed in this study. The dampers are located at the top and first floors for MTMD12, more dampers are located at the top and second floors for
MTMD13, and further dampers are located at all structural floors for MTMD123.

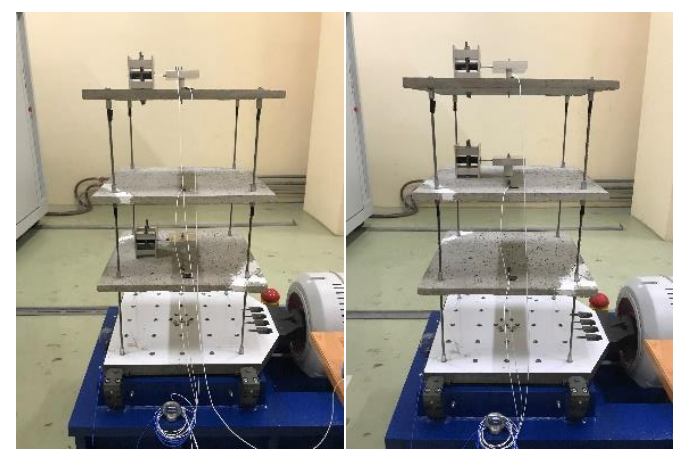

(a)

(b)

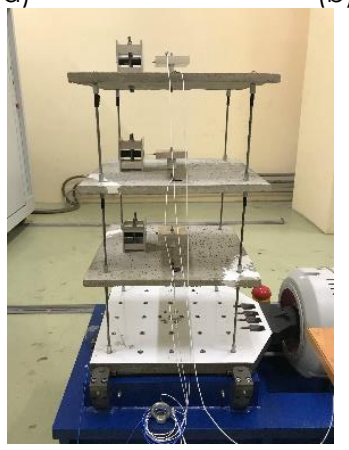

(c)

Figure 11 Arrangements of Single TMD (a) TMD1 (b) TMD2 (c) TMD3

It is observed that the reduction in both RMS acceleration and displacement of the structural floors were achieved significantly for all multiple TMD cases. In all TMD configurations, dampers closely tuned to the desire natural frequencies of the uncontrolled primary structure. This finding suggests that mass dampers can effectively regulate higher vibration modes with the implementation of multiple TMD configurations. The test results in Table 5 show that the two tuning frequency ratios produce nearly identical controlled structure responses. There may be two explanations for this. First, the fundamental mode accounts for a significant portion of the structural response, typically the highest. The structural responses of the second mode are less sensitive to changes in dynamic characteristics than those of the first mode. Second, the base excitation used in the experiments has a dominant frequency that is equal to the structure's fundamental frequency, resulting in a more uniform energy distribution across the structure's second natural frequency. As a result, for the second mode TMD, the sensitivity of floor acceleration to changes in frequency ratio is lower. It is revealed that when the building system is subjected to ground excitation, all dampers perform substantially better for the same reasons as discussed for the first-mode dampers. Under these loadings, the RMS acceleration at the top floor can be decreased by 37 to 50 percent while the RMS displacement can be reduced by 29 to 58 percent. Since the MTMD1239 attained the best performance in terms of RMS acceleration reduction 
compared to the rest cases, it can be stated that the greater the number of substructures, the more reduction in both RMS acceleration and displacement responses of the primary structure. For the cases of multiple TMD, the amplitudes at natural frequencies are smaller than the single TMD cases. This show that the multiple TMD cases has the best broadband vibration control effects. This fact will be further discussed in terms of Peak Response Ratio (PRR) within the next section. Figure 12 show the time domain responses of TMD1239 mechanism compared to the uncontrolled primary structure.

Table 5 RMS Acceleration and Displacement Reduction of Different Multiple TMD Cases

\begin{tabular}{|c|c|c|c|}
\hline TMD & Floor & $\begin{array}{c}\text { RMS } \\
\text { Acceleration } \\
\text { Reduction (\%) }\end{array}$ & $\begin{array}{c}\text { RMS } \\
\text { Displacement } \\
\text { Reduction (\%) }\end{array}$ \\
\hline \multirow{3}{*}{ MTMD122 } & 1 & 39.58 & 50.80 \\
\cline { 2 - 4 } & 2 & 38.09 & 49.89 \\
\cline { 2 - 4 } & 3 & 37.77 & 36.61 \\
\hline \multirow{3}{*}{ MTMD132 } & 1 & 44.38 & 8.79 \\
\cline { 2 - 4 } & 2 & 48.17 & -0.98 \\
\cline { 2 - 4 } & 3 & 50.36 & 29.55 \\
\hline MTMD1239 & 1 & 44.19 & 28.00 \\
\cline { 2 - 4 } & 2 & 44.89 & 45.83 \\
\cline { 2 - 4 } & 3 & 45.45 & 58.11 \\
\hline
\end{tabular}
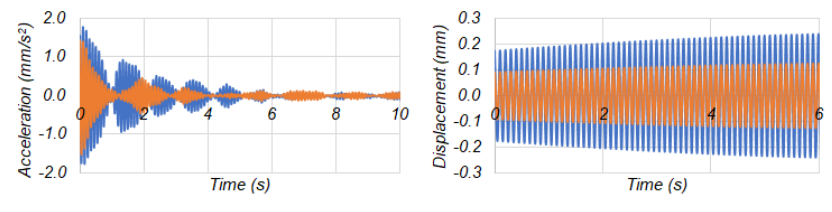

—PS 1st Floor —MTMD1239 1st Floor
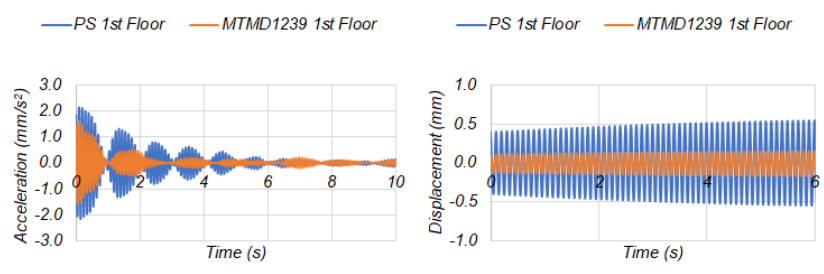

-PS 2nd Floor - MTMD1239 2nd Floor
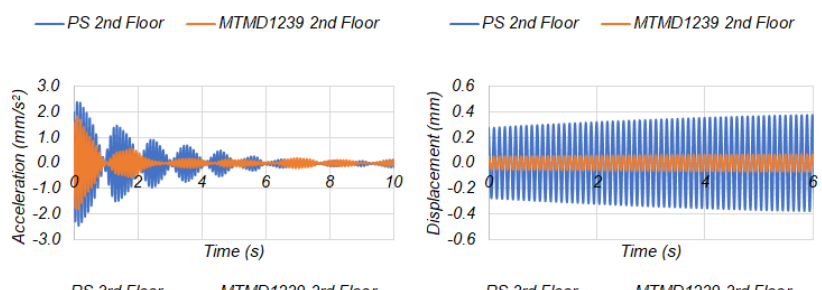

—PS 3rd Floor —MTMD1239 3rd Floor

—PS 3rd Floor —MTMD1239 3rd Floor

Figure 12 Acceleration and displacement responses of TMD1239 mechanism

The peak dynamic responses of the bare frame at various floors are compared to the single TMD controlled frames in this section. Figure 13 shows the Peak Responses Ratio of each structural floor for the TMD18 arrangement. The TMD is placed in the mode antinode, which is where it is most effective. The existence of TMD18 lowered the first and third vibration modes of the uncontrolled main structure, except for the second mode, which contributes to further structural amplification, as seen in the figure. The TMD27 arrangement as shown in Figure 14 increased the first mode while reducing all structural floors for dedicated second and third vibration modes. In comparing the TMD27, Figure 15 depicts that the TMD35 amplifies the first structural mode but it is observable that the second mode slightly increased. However, the TMD35 mechanism is able to lower the peak response of its dedicated mode. These findings suggest that distinct structural modes have varying degrees of importance in determining overall responses. The most effective TMD is one that is adjusted to the most dominant structural mode. The structural responses seen are marginally degraded by the presence of a single TMD for other non-dedicated structural modes accordingly. Structural vibration control performance was also influenced by the inherent primary structure frequencies and the frequency range of the ground vibration. The presence of a TMD may not produce substantial response reduction if the excitation frequency is depreciated away from inherent frequencies of the structure.
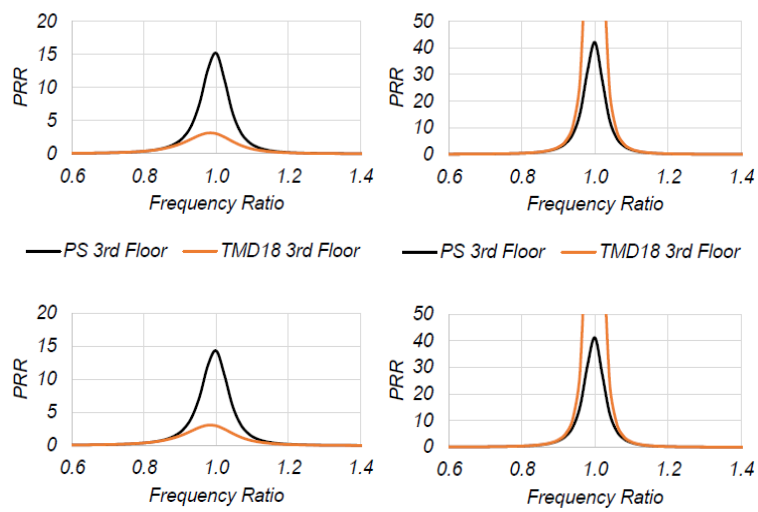

—PS 3rd Floor —TMD18 3rd Floor
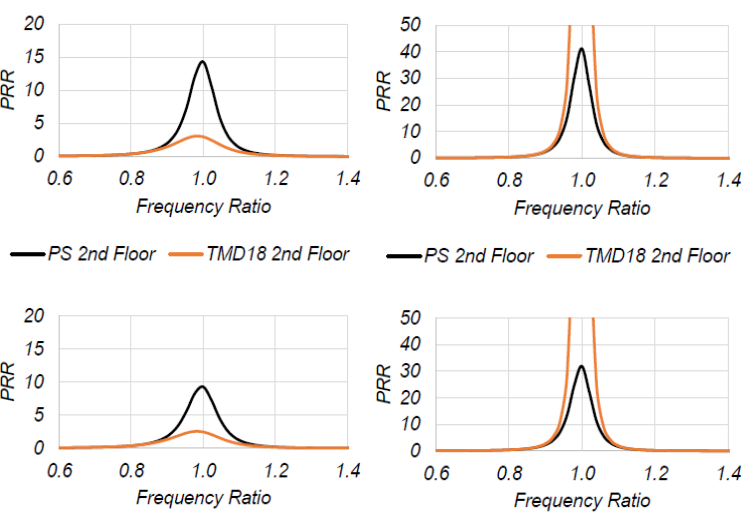

-PS 1st Floor -TMD18 1st Floor

(a)

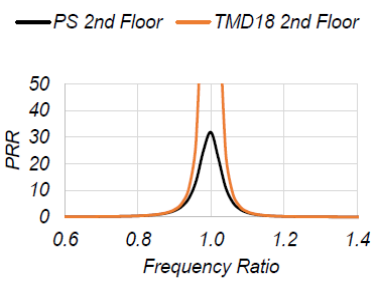

-PS 1st Floor -TMD18 1st Floor

(b) 


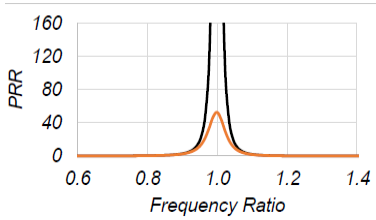

—PS 3rd Floor —TMD18 3rd Floor

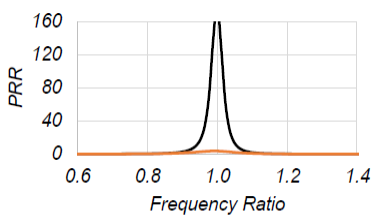

—PS 2nd Floor TMD18 2nd Floor

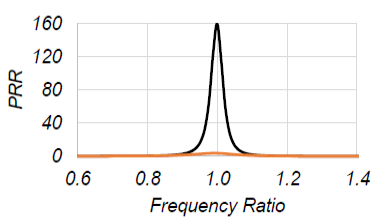

-PS 1st Floor —TMD18 1st Floor

(c)

Figure 13 Effect of TMD18 on the Peak Response Ratio of the PS; (a) $1^{\text {st }}$ Mode; (b) 2nd Mode; (c) 3rd Mode
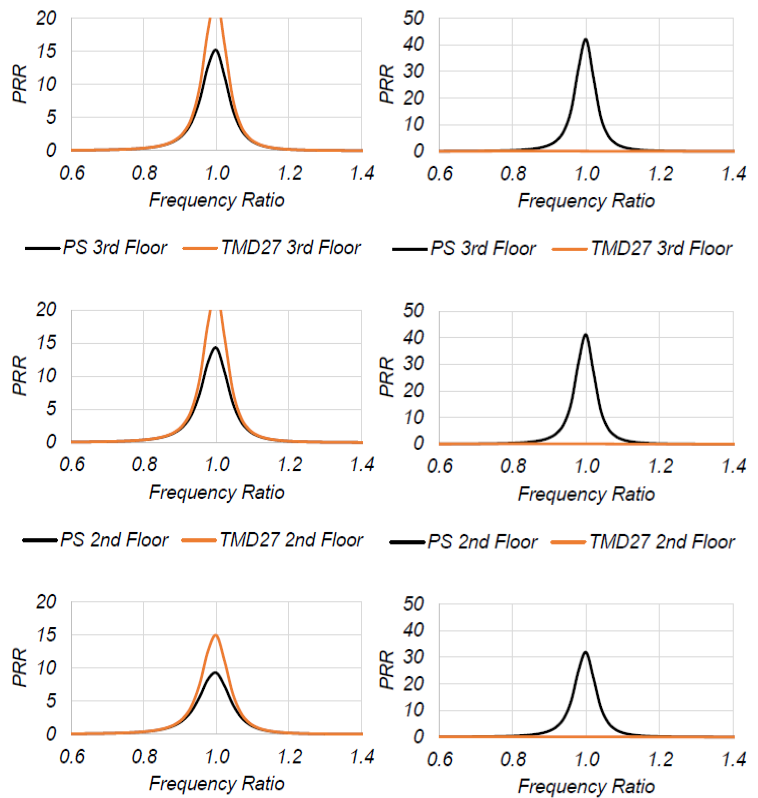

—PS 1st Floor —TMD27 1st Floor

(a) (b)
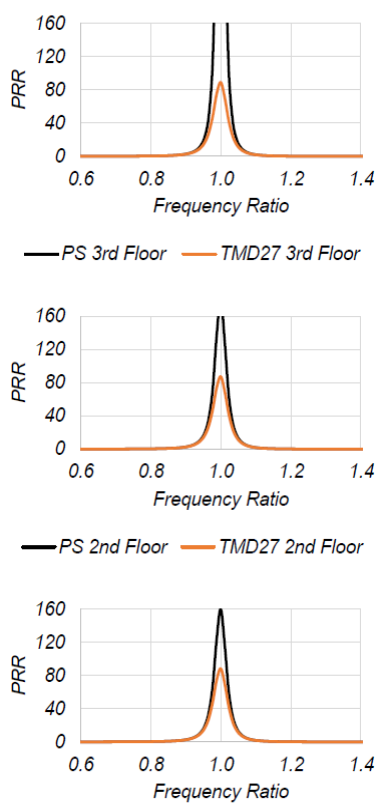

-PS 1st Floor —TMD27 1st Floor (c)

Figure 14 Effect of TMD27 on the Peak Response Ratio of the PS; (a) $1^{\text {st }}$ Mode; (b) 2nd Mode; (c) 3rd Mode
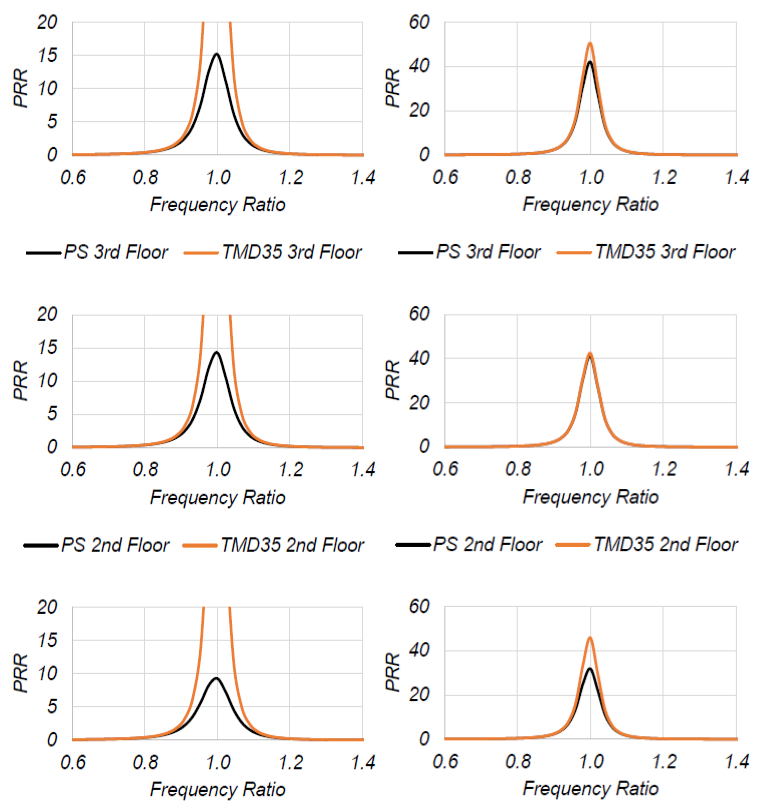

-PS 1st Floor —TMD35 1st Floor

(a)

(b) 


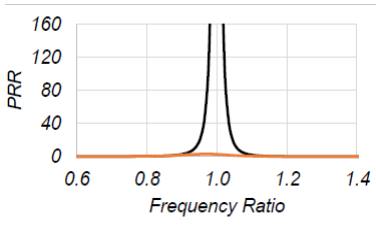

—PS 3rd Floor —TMD35 3rd Floor

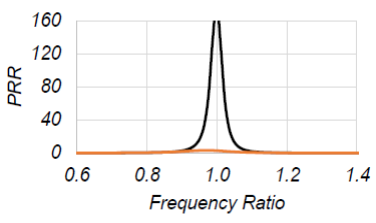

—PS 2nd Floor —TMD35 2nd Floor

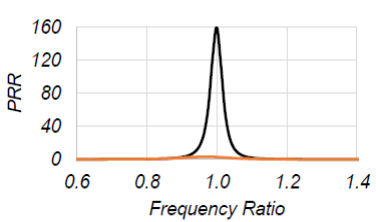

-PS 1st Floor —TMD35 1st Floor

(c)

Figure 15 Effect of TMD35 on the Peak Response Ratio of the PS; (a) $1^{\text {st }}$ Mode; (b) 2nd Mode; (c) 3rd Mode

The inclusion of a single TMD does not result in structural frame response reduction for non-dedicated modes, as determined by the previous peak response ratio data analysis. Therefore, the deployment of a multiple TMD mechanism is investigated in this section to see if structural multimode response reductions are possible. Within this study, three cases of multiple TMD arrangements have been considered, labelled as; MTMD12 which refers to the TMDs located at the third and first floors; MTMD13 refers to the TMDs located at the third and second floors; and MTMDI23 which indicates to the TMDs located at all structural floors simultaneously. The structural response was measured over a varying range which covers all three uncontrolled structural natural frequencies. Figure 16 shows the comparison of structural response between the uncontrolled primary structure to the one equipped with the MTMD12 mechanism and air damper tuned to level 2 (MTMD122). It can be observed from the figure that the MTMD122 mechanism is capable of reducing responses of all structural floors for all structural modes. When compared to singular mechanism of TMD18, the suggested mechanism's ability to reduce first mode vibrations is increased by 16 to 25 percent while the structural floors reduction for both second and third modes revealed that the existence of TMD at the first floor contributed to the overall performance. For the case of MTMD13 where air damper tuned to level 2 (MTMD132) as per Figure 17, the reduction of structural floors for the first and third mode are significant but subsequently declining compared to the MTMD122 case while for the second mode, the peak response is depreciated. Furthermore, in reference to the structural peak response from Figure 18, the implementation of MTMD123 with air damper tuned to level 9 (MTMD1239) significantly contributed to the reduction of all structural floor responses at its natural frequencies. It is found that by positioning TMDs on a consecutive floor of the primary structure resulted in significantly more structural damping and enhance the suppression bandwidth of the overall vibration control system.
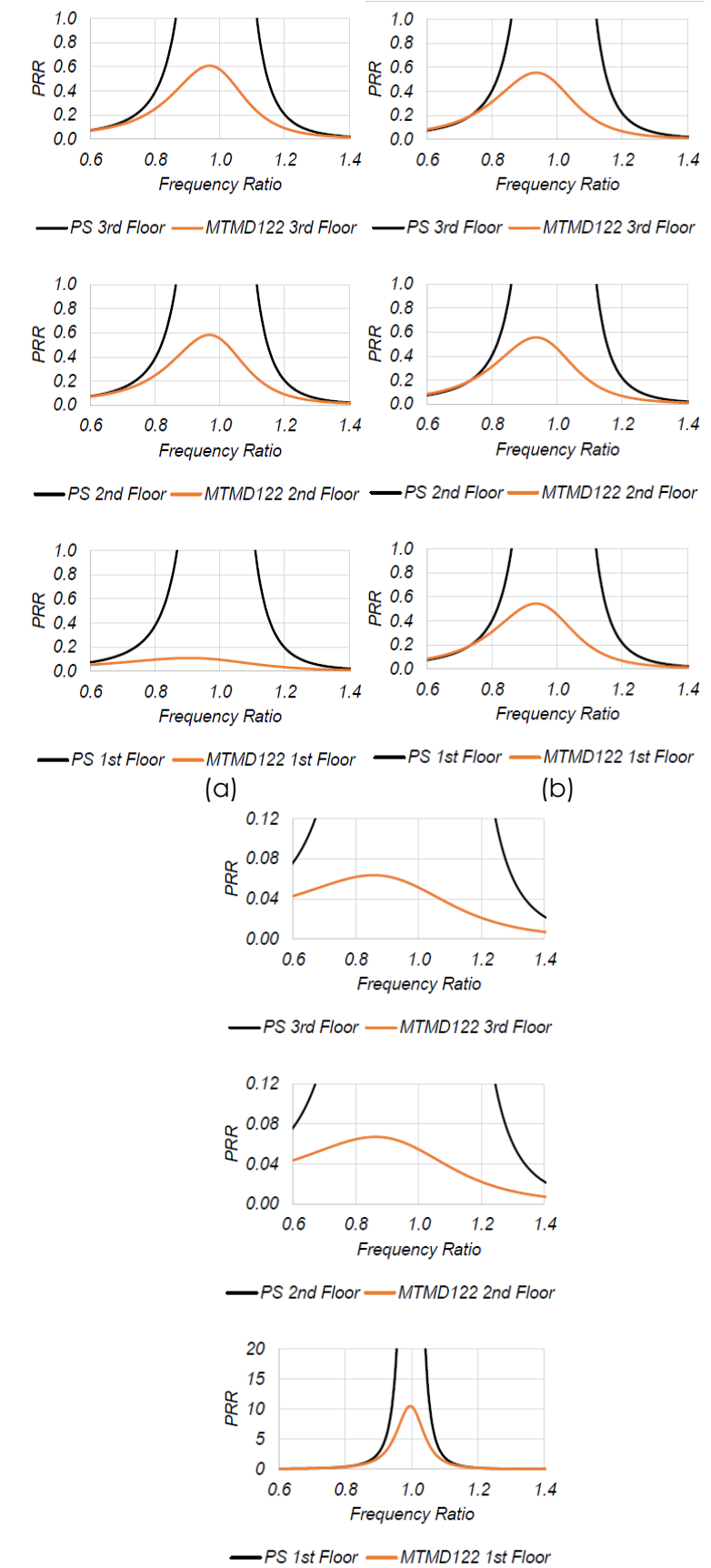

(c)

Figure 16 Effect of MTMD 122 on the Peak Response Ratio of the PS; (a) 1 15t Mode; (b) 2nd Mode; (c) 3rd Mode 

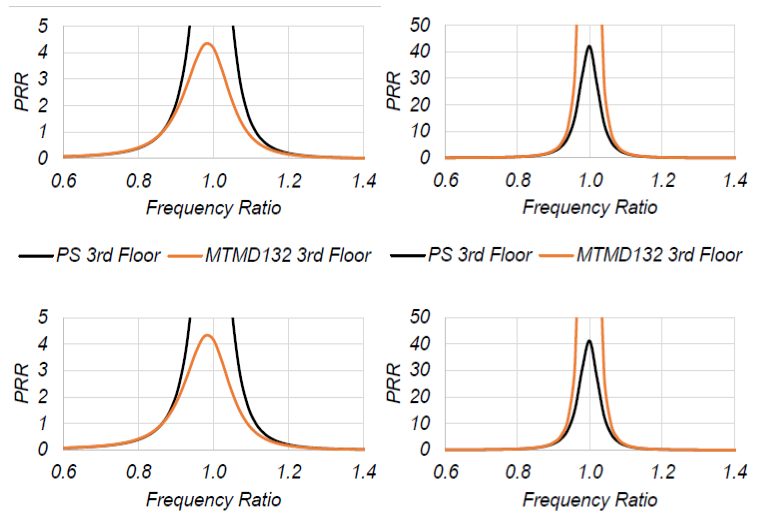

—PS 2nd Floor — MTMD132 2nd Floor —PS 2nd Floor — MTMD132 2nd Floor
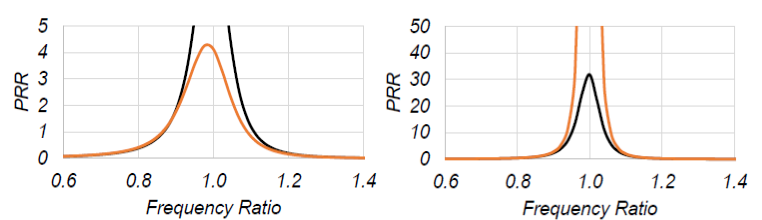

—PS 1st Floor — MTMD132 1st Floor

(a)

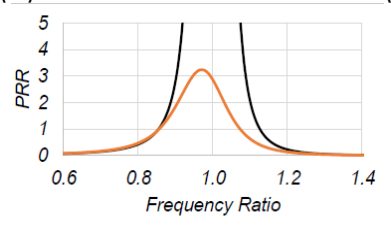

—PS 3rd Floor —MTMD132 3rd Floor

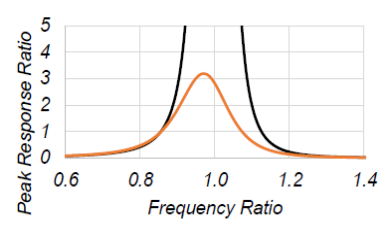

—PS 2nd Floor — MTMD132 2nd Floor

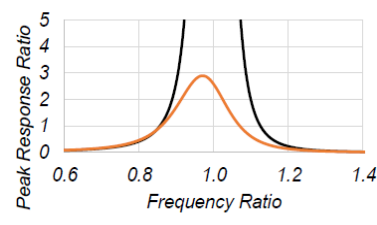

-PS 1st Floor —MTMD132 1st Floor

(c)

Figure 17 Effect of MTMD132 on the Peak Response Ratio of the PS; (a) $1^{\text {st }}$ Mode; (b) 2nd Mode; (c) 3rd Mode
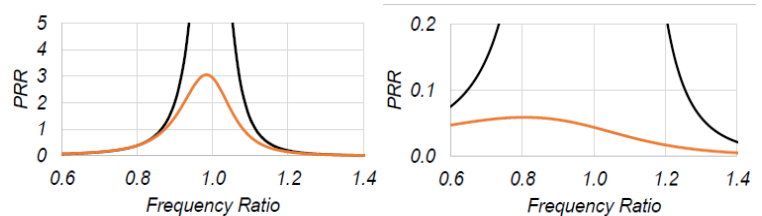

—PS 3rd Floor — MTMD1239 3rd Floor
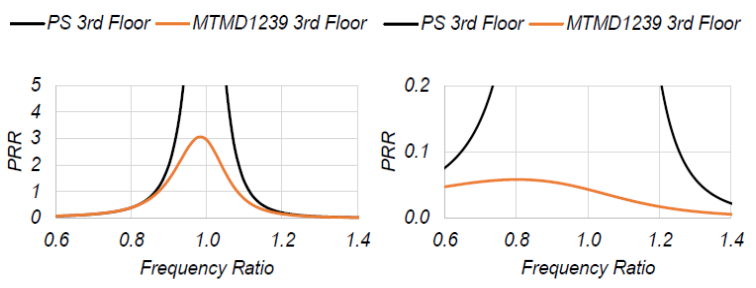

—PS 2nd Floor — MTMD1239 2nd Floor —PS 2nd Floor — MTMD1239 2nd Floor
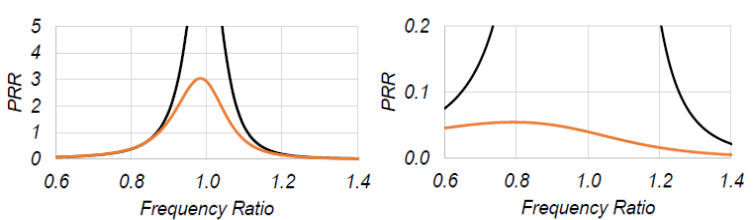

-PS 1st Floor —MTMD1239 1st Floor

(a)

(b)

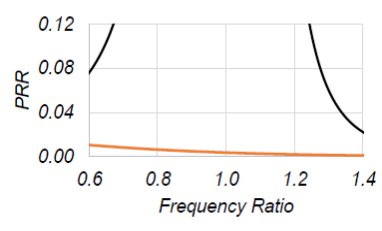

-PS 3rd Floor — MTMD1239 3rd Floo

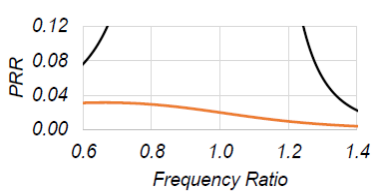

-PS 2nd Floor

- MTMD1239 2nd Floor

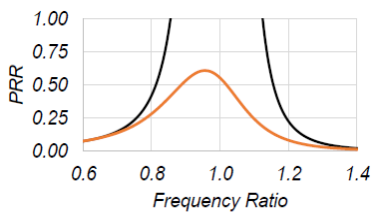

-PS 1st Floor - MTMD12391st Floor

(c)

Figure 18 Effect of MTMD1239 on the Peak Response Ratio of the PS; (a) $1^{\text {st }}$ Mode; (b) 2nd Mode; (c) 3rd Mode 
In reference to Table 6, it can be concluded that when the damping ratio increases, the structural vibration response decreases exponentially. For the case of TMD18 which was initially designed to suppress the fundamental mode, the combination of a single TMD mechanism increased the overall structural damping which benefit the attenuation of structural drift to a certain extent. Furthermore, the performance of a single TMD is proven to be enhanced by the implementation of multiple TMD arrangement as shown in the TMD1239 data. Within the range of frequency ratio equal or smaller than 1.2 , if the damping ratio of the while the peak response ratio is larger, the structural vibration is characterized by amplification effect. Otherwise, if the damping ratio is larger and the peak response ratio is smaller, it is classified as attenuation effect. Therefore, the proposed multiple TMD1239 is the most effective energy dissipation mechanism within the cases which provide sufficient damping for multimode structural vibration control.

Table 6 Frequency Ratio and Damping Ratio of Uncontrolled Structure, TMD12, and TMD1239 for each of Structural Floors

\begin{tabular}{|l|c|c|c|c|c|c|}
\cline { 2 - 7 } & \multicolumn{6}{c|}{ Uncontrolled Structure } \\
\cline { 2 - 7 } & \multicolumn{3}{|c|}{ Frequency Ratio } & \multicolumn{2}{c|}{ Damping Ratio } \\
\cline { 2 - 7 } & $\begin{array}{c}\text { MODE } \\
\mathbf{1}\end{array}$ & $\begin{array}{c}\text { MODE } \\
\mathbf{2}\end{array}$ & $\begin{array}{c}\text { MODE } \\
\mathbf{3}\end{array}$ & $\begin{array}{c}\text { MODE } \\
\mathbf{1}\end{array}$ & $\begin{array}{c}\text { MODE } \\
\mathbf{2}\end{array}$ & $\begin{array}{c}\text { MODE } \\
\mathbf{3}\end{array}$ \\
\hline $\begin{array}{l}\text { 1st } \\
\text { Floor }\end{array}$ & 1.0000 & 1.0000 & 1.0000 & 0.0646 & 0.0428 & 0.0298 \\
\hline $\begin{array}{l}\text { 2nd } \\
\text { Floor }\end{array}$ & 1.0000 & 1.0000 & 1.0000 & 0.0559 & 0.0393 & 0.0279 \\
\hline $\begin{array}{l}\text { 3rd } \\
\text { Floor }\end{array}$ & 1.0000 & 1.0000 & 1.0000 & 0.0548 & 0.0390 & 0.0267 \\
\hline
\end{tabular}

\begin{tabular}{|l|l|c|c|c|c|c|}
\cline { 2 - 7 } \multicolumn{1}{c|}{} & \multicolumn{6}{c|}{ TMD18 } \\
\cline { 2 - 7 } \multicolumn{1}{c|}{} & \multicolumn{3}{c|}{ Frequency Ratio } & \multicolumn{3}{c|}{ Damping Ratio } \\
\cline { 2 - 7 } & $\begin{array}{c}\text { MODE } \\
\mathbf{1}\end{array}$ & $\begin{array}{c}\text { MODE } \\
\mathbf{2}\end{array}$ & $\begin{array}{c}\text { MODE } \\
\mathbf{3}\end{array}$ & $\begin{array}{c}\text { MODE } \\
\mathbf{1}\end{array}$ & $\begin{array}{c}\text { MODE } \\
\mathbf{2}\end{array}$ & $\begin{array}{c}\text { MODE } \\
\mathbf{3}\end{array}$ \\
\hline $\begin{array}{l}\text { 1st } \\
\text { Floor }\end{array}$ & 0.9765 & 1.0000 & 1.0000 & 0.1803 & 0.0207 & 0.0886 \\
\hline $\begin{array}{l}\text { 2nd } \\
\text { Floor }\end{array}$ & 0.9773 & 1.0000 & 1.0000 & 0.1740 & 0.0208 & 0.0878 \\
\hline $\begin{array}{l}\text { 3rd } \\
\text { Floor }\end{array}$ & 0.9774 & 1.0000 & 1.0000 & 0.1733 & 0.0213 & 0.0362 \\
\hline
\end{tabular}

\begin{tabular}{|l|c|c|c|c|c|c|}
\cline { 2 - 7 } \multicolumn{1}{c|}{} & \multicolumn{6}{c|}{ TMD1239 } \\
\cline { 2 - 7 } \multicolumn{1}{c|}{} & \multicolumn{3}{|c|}{ Frequency Ratio } & \multicolumn{3}{c|}{ Damping Ratio } \\
\cline { 2 - 7 } \multicolumn{1}{c|}{} & $\begin{array}{c}\text { MODE } \\
\mathbf{1}\end{array}$ & $\begin{array}{c}\text { MODE } \\
\mathbf{2}\end{array}$ & $\begin{array}{c}\text { MODE } \\
\mathbf{3}\end{array}$ & $\begin{array}{c}\text { MODE } \\
\mathbf{1}\end{array}$ & $\begin{array}{c}\text { MODE } \\
\mathbf{2}\end{array}$ & $\begin{array}{c}\text { MODE } \\
\mathbf{3}\end{array}$ \\
\hline $\begin{array}{l}\text { 1st } \\
\text { Floor }\end{array}$ & 0.9772 & 0.8553 & 0.9433 & 0.1745 & 0.5398 & 0.2842 \\
\hline $\begin{array}{l}\text { 2nd } \\
\text { Floor }\end{array}$ & 0.9773 & 0.8575 & 0.8804 & 0.1743 & 0.5312 & 0.6044 \\
\hline $\begin{array}{l}\text { 3rd } \\
\text { Floor }\end{array}$ & 0.9773 & 0.8583 & 0.8156 & 0.1743 & 0.5283 & 0.9337 \\
\hline
\end{tabular}

\subsection{CONCLUSION}

The performance investigation of the newly proposed TMD mechanism consisting of TPU bearing, aluminium mass, and air dashpot has been conducted using the Experimental Modal Analysis (EMA) procedures. Initially, primary structure is designed and validated for dynamic properties identification. The TPU bearing is then designed according to the first three identical structural modes. Next, the assembly of the proposed TMD mechanism is then investigated through different cases that generally can be divided into two major categories which are single TMD and multiple TMD. By referring to the presented and analysed data from the previous sections, it can be concluded that it is more beneficial to set a single TMD on sequential maximum displacements of the structural floor for each of the targeted structural vibration modes in order to reduce structural response. Therefore, the fundamental mode needs to be prioritized since the maximum structural response located at the top floor. However, the drawback of using a single TMD is that the controllable excitation range is limited to a narrowband frequency. The desired valve position of the air damper and TPU bearing design are crucial in order to achieve an optimized damping condition of both single and multiple TMD mechanism. For the single TMD mechanism, it is observed that the TMD3 with air damper adjusted to level 5 is capable of controlling top floor structural responses for both RMS acceleration and RMS displacement of $41.94 \%$ and $71.33 \%$. Nevertheless, for multiple TMD cases, the MTMD123 with air damper adjusted to level 5 depicted significant reduction of both RMS acceleration and RMS displacement with $45.45 \%$ and $58.11 \%$.

The frequency at which the MTMDs are tuned determines the relative performance of a given MTMD arrangement. Nonetheless, for a specific MTMD configuration such as TMD132, it is effective at attenuating structural response when tuned to the first and the third mode uncontrolled frequencies. In reference to the graph in Figure 17, it is worthy to mention that the Peak Response Ratio may cause structural response amplification for the second mode. However, in this case, the performance of the multiple TMD arrangements is much better compared to the stand alone TMDs. Tuning multiple TMDs to a higher system mode frequency rather than the fundamental mode system frequency can be more effective. It is because each TMD has its unique dynamic parametric properties which can benefit the vibration control mechanism as a whole. The capabilities of the proposed multiple TMDs to control wider bandwidth excitation can be observed from the RMS acceleration, RMS displacement, and peak response ratio data analysis. To justify the attenuation of structural peak response at resonance, the peak response ratio analysis depicted the potential of the proposed multiple TMDs accordingly.

\section{References}

[1] S. Elias and V. Matsagar. 2017. Research Developments in Vibration Control of Structures Using Passive Tuned Mass Dampers. Annu. Rev. Control. 44: 129-156. Doi: 
10.1016/j.arcontrol.2017.09.015.

[2] T. Igusa and K. XU. 1994. Vibration Control Using Multiple Tuned Mass Dampers. J. Sound Vib. 175(4): 491-503.

[3] W. Ma, J. Yu, and Y. Yang. 2021. Graphical Design Methodology of Multi-Degrees-of-Freedom Tuned Mass Damper for Suppressing Multiple Modes. J. Vib. Acoust. Trans. ASME. 143(1). Doi: 10.1115/1.4047860.

[4] Y. Liu, K. Wang, O. Mercan, H. Chen, and P. Tan. 2019 Experimental and Numerical Studies on the Optimal Design of Tuned Mass Dampers for Vibration Control of High-rise Structures. Eng. Struct. 211(September): 110486. Doi: 10.1016/j.engstruct.2020.110486.

[5] Y. Fujino and M. Abé. 1993. Design Formulas for Tuned Mass Dampers Based on a Perturbation Technique. Earthq. Eng. Struct. Dyn. 22(10): 833-854. Doi: 10.1002/eqe.4290221002.

[6] A. Kareem and S. Kline. 1995. Performance of Multiple Mass Dampers Under Random Loading. J. Struct. Eng. 121 (2): 348361,

[7] A. S. Joshi and R. S. Jangid. 1997. Optimum Parameters of Multiple Tuned Mass Dampers for Base-Excited Damped Systems. Journal of Sound and Vibration. 202(5): 657-667. https://doi.org/10.1006/jsvi.1996.0859

[8] C. Li. 2002. Optimum Multiple Tuned Mass Dampers for Structures Under the Ground Acceleration based on DDMF and ADMF. Earthq. Eng. Struct. Dyn. 919(November 2000): 897-919. Doi: 10.1002/eqe.128.

[9] L. Hong-nan and N. Xiang-lei. 2007. Optimization of Nonuniformly Distributed Multiple Tuned Mass Damper. 308: 8097. Doi: 10.1016/j.jsv.2007.07.014

[10] C. Lin, J. Wang, C. Lien, and H. Chiang. 2010. Optimum Design and Experimental Study of Multiple Tuned Mass Dampers With Limited Stroke. April: 1631-1651. Doi: 10.1002/eqe.

[11] L. Wang, W. Shi, Q. Zhang, and Y. Zhou. 2020. Study on Adaptive-passive Multiple Tuned Mass Damper with Variable Mass for a Large-span Floor Structure. Eng. Struct. 209(December 2019): $110010 . \quad$ Doi: 10.1016/j.engstruct.2019.110010.

[12] T. H. Nguyen, I. Saidi, E. F. Gad, J. L. Wilson, and N. Haritos. 2012. Performance of Distributed Multiple Viscoelastic Tuned Mass Dampers for Floor Vibration Applications. Advances in Structural Engineering.15(3): 547-562. https://doi.org/10.1260/1369-4332.15.3.547.

[13] A. Xiang, P., Nishitani. 2013. Seismic Vibration Control of Building Structures with Multiple Tuned Mass Damper Floors Integrated. Int. Assoc. Earthq. Eng. Doi: 10.1002/eqe.

[14] S. Elias and V. Matsagar. 2014. Wind Response Control of 76Storey Benchmark Building with Distributed Multiple Tuned Mass Dampers. J. Wind Eng. 11 (July): 37-49. Doi: 10.3850/978981-07-8012-8.

[15] S. Elias, V. Matsagar, and T. K. Datta. 2016. Effectiveness of Distributed Tuned Mass Dampers for Multi-mode Control of Chimney Under Earthquakes. Eng. Struct. 124: 1-16. Doi: 10.1016/j.engstruct.2016.06.006.

[16] T. A. Sakr. 2017. Vibration Control of Buildings by Using Partial Floor Loads as Multiple Tuned Mass Dampers. HBRC J. 13(2): 133-144. Doi: 10.1016/j.hbrcj.2015.04.004.

[17] D. Gill, S. Elias, A. Steinbrecher, C. Schröder, and V. Matsagar. 2017. Robustness of Multi-mode Control using Tuned Mass Dampers for Seismically Excited Structures. Bull. Earthq. Eng. 15(12): 5579-5603. Doi: 10.1007/s10518-017-0187-6.

[18] B. Wen, M. A. Moustafa, and D. Junwu. 2018. Seismic Response of Potential Transformers and Mitigation Using Innovative Multiple Tuned Mass Dampers. Eng. Struct. 174(July): 67-80. Doi: 10.1016/j.engstruct.2018.07.034.

[19] L. S. Vellar, S. P. Ontiveros-Pérez, L. F. F. Miguel, and L. F. Fadel Miguel. 2019. Robust Optimum Design of Multiple Tuned Mass Dampers for Vibration Control in Buildings Subjected to Seismic Excitation. Shock Vib. Doi: 10.1155/2019/9273714.

[20] L. Suresh and K. M. Mini. 2019. Effect of Multiple Tuned Mass Dampers for Vibration Control in High-Rise Buildings. Pract Period. Struct. Des. Constr. 24(4): 04019031. Doi: 10.1061 /(asce)sc.1943-5576.0000453.

[21] V. Jahangiri and C. Sun. 2020. Three-dimensional Vibration Control of Offshore Floating Wind Turbines using Multiple Tuned Mass Dampers. Ocean Eng. 206(April): 107196. Doi: 10.1016/j.oceaneng.2020.107196.

[22] S. Y. Kim and C. H. Lee. 2020. Analysis and Optimization of Multiple Tuned Mass Dampers with Coulomb Dry Friction. Eng. Struct. 209(December 2019): 110011. Doi: 10.1016/j.engstruct.2019.110011.

[23] M. Khazaei, R. Vahdani, and A. Kheyroddin. 2020. Optimal Location of Multiple Tuned Mass Dampers in Regular and.pdf. Shock Vib. 2020.

[24] A. Z. Ahmad, A. Abu, L. K. Quen, N. A. Othman, and F. C. In 2019. Numerical Modelling of Multiple Tuned Mass Damper Equipped with Magneto Rheological Damper for Attenuation of Building Seismic Responses. J. Teknol. 81(6): 103-113. Doi: 10.11113/jt.v81.13786.

[25] G. J. G. Jin, M. K. Sain, and B. F. J. Spencer. 2005. Frequency Domain System Identification for Controlled Civil Engineering Structures. IEEE Trans. Control Syst. Technol. 13(6):1055-1062. Doi: 10.1109/TCST.2005.854341.

[26] B. Li, K. Dai, J. Meng, K. Liu, J. Wang, and S. Tesfamariam. 2020. Simplified Design Procedure for Nonconventional Multiple Tuned Mass Damper and Experimental Validation. Struct. Des. Tall Spec. Build. October: 1-14. Doi: 10.1002/tal.1818.

[27] M. W. L. M. Rijnen, F. Pasteuning, R. H. B. Fey, G. Van Schothorst, and H. Nijmeijer. 2014. A Numerical and Experimental Study on Passive Damping of a 3D Structure using Viscoelastic Materials. Proc. ISMA 2014 - Int. Conf. Noise Vib. Eng. USD 2014 - Int. Conf. Uncertain. Struct. Dyn. 597-610.

[28] G. Hathaway. 2013. Chapter 8: Modal Analysis MethodsFrequency Domain. Vol. 2. 